\title{
¿MÁs Deberes o MÁs DERECHOS? Diez AÑos de CONFLICTIVA REgUlación estatal de la PATERnidad en Chile, Costa Rica Y URUGUAY*
}

\author{
Expanded duties or expanded rights? A decade of conflicting state \\ regulations of fatherhood in Chile, Costa Rica and Uruguay
}

\author{
JULIANA MARTÍNEZ FRANZONI
}

Universidad de Costa Rica

\section{ADRIANA FERNÁNDEZ CALDERÓN}

Universidad de Costa Rica

\begin{abstract}
RESUMEN
En la última década, el papel del Estado respecto al ejercicio paterno ha sido abordado por múltiples actores con un creciente poder político. La paternidad, sus defectos y los sesgos en su contra, han sido vinculados a problemas sociales que trascienden a la propia familia, como la pobreza infantil y la violencia doméstica. La literatura comparada relativa a los procesos políticos recientes en esta materia en América Latina es, hasta ahora, prácticamente inexistente. A partir de las fuentes legislativas, este artículo analiza una década de transformaciones en la regulación estatal de la paternidad en Chile, Costa Rica y Uruguay en escenarios parentales conflictivos, y examina los procesos políticos que explican sus variaciones. El artículo concluye que medidas para promover deberes ó derechos paternos reflejaron la orientación política de partidos políticos y poder ejecutivos de izquierda y conservadores, respectivamente.
\end{abstract}

Palabras clave: Estado, regulación, paternidad, América Latina.

\begin{abstract}
In the last decade, the role of the State regarding paternity was addressed by presidents, congresses and civil society actors with increasing political power. Fatherhood and the defects and biases against it have been linked to social problems that transcend the family itself, such as child poverty and domestic violence. The comparative literature on recent political processes on this matter, however, is practically non-existent. Based on primary sources, this article analyzes a decade of transformation in the regulation of male breadwinning and care-giving, particularly when parenting goes to courts in Chile, Costa Rica and Uruguay, linking both to the political processes and accounting for their important variations. The article concludes that measures to promote parental rights or duties reflected the political orientation of left and conservative political parties and executive powers, respectively.
\end{abstract}

Keywords: State, regulation, fatherhood, Latin America.

Agradecimientos: Este artículo se elaboró desde el Instituto de Investigaciones Sociales y contó con el apoyo del Fondo de Estímulo de la Vicerrectoría de Investigación de la Universidad de Costa Rica. Agradecemos los valiosos aportes de tres revisores anónimos, la lectura de Wendy León, y la asistencia de Cristina González. Los errores y omisiones son de las autoras. 


\section{INTRODUCCIÓN}

La definición de derechos y responsabilidades paternas incide en las reglas sociales sobre la reproducción y la sexualidad, las relaciones de género, y el papel esperado de hombres y mujeres en las familias y los mercados laborales. Durante el siglo veinte, la regulación estatal de la paternidad fue polémica: en momentos de grandes transformaciones políticas los hombres en tanto padres fueron sujetos de escrutinio público en directa relación con graves problemas sociales como mortalidad, maltrato y pobreza infantil y materna (Bliss 1999; Birn 2012; Milanich 2015). Entonces y ahora, los padres respondieron de distintas maneras, incluso incidiendo de manera organizada en los procesos de formación de política (Bliss, 1999).

Iniciando el siglo veintiuno, dependiendo de los países, entre el 40 y el 85 por ciento de las madres latinoamericanas criaban niños y adolescentes sin apoyo económico paterno (Buchelli y Vigorito 2017; Cuesta, Jokela, y otros 2019; Martínez Franzoni 2021). Una combinación de preocupaciones respecto al bienestar infantil, nutrieron medidas que cambiaron esta situación. Paralelamente, organizaciones de padres que no residen con sus hijos/as denunciaron sesgos y buscaron cambiar leyes (León, 2020). Nos interesa analizar la regulación de la paternidad en ausencia de conyugalidad porque hace más visible el abordaje estatal de la paternidad propiamente dicha, así como por sus altos niveles de conflictividad actual.

Históricamente, estas responsabilidades parentales reflejan el "contrato sexual" (Pateman, 1988) mediante el cual el Estado explícita o implícitamente establece las reglas que gobiernan las relaciones de género. Este contrato ha organizado los derechos y obligaciones maternas y paternas mediante una especialización jerárquica de funciones basada en la división sexual del trabajo (Folbre, 2012). Es a través de esta especialización que los Estados construyen tanto la maternidad como la paternidad (Hobson \& Morgan, 2002). Allí donde el Estado aborda la familia como principal proveedora de bienestar, estas definiciones tienen implicancias significativas para la distribución de recursos como el tiempo y los ingresos.

En Chile, Uruguay y Costa Rica, tres países latinoamericanos con alto desarrollo social, la enorme mayoría de niños y niñas son criados por sus madres ( $\mathrm{Li}$ ppman \& Wilcox, 2014). A la vez, el 40, 50 y $60 \%$ de menores carecen de apoyo económico paterno, respectivamente (Cuesta y Meyer 2014; Buchelli y Vigorito 2017). La regulación estatal hacia el 2018 era variable: en estos tres países el Estado regulaba la paternidad bajo supuestos de género distintos (Martínez Franzoni, 2021). Costa Rica establecía relaciones de complementariedad a partir de una marcada división sexual del trabajo entre madres y padres. Chile y Uruguay de distinta manera, habían tomado medidas para igualar roles. En Chile los padres obtuvieron la tenencia compartida aún en casos de conflicto parental; en Uruguay se generaron mejores condiciones para el ejercicio de la paternidad previo conflicto parental. El resultado fue de complementariedad 
en Costa Rica, de corresponsabilidad consistente en Uruguay, y de complementariedad híbrida en Chile (Martínez Franzoni, 2021; Martínez Franzoni \& Arias, 2021). ${ }^{1}$

Este artículo aborda las transformaciones y dinámicas políticas que experimentaron estos tres países durante la última década, y que les llevaron a adoptar medidas distintas y con implicaciones variables para la igualdad de género en la regulación del ejercicio de la paternidad. A continuación, discutimos la literatura, explicamos la metodología seguida de los hallazgos, análisis y conclusiones.

\section{EL ESTADO Y LA REGULACIÓN DE LA PATERNIDAD}

Aún en países con políticas sociales robustas, la mayor parte del bienestar de las personas latinoamericanas, depende de recursos familiares de tiempo y dinero, ambos regulados fuertemente en el derecho de familia. Su orientación depende de varios factores. La ideología diferencia preferencias, tanto respecto a las relaciones de género esperadas, como al papel del Estado en la vida familiar. Mientras los partidos políticos de izquierda suelen combatir la desigualdad y las jerarquías de género, los partidos conservadores - religiosos o no -, generalmente favorecen una menor intervención estatal y apoyan la especialización entre hombres proveedores y mujeres cuidadoras (Michell y Mahon 2002; Kramerman y Moss 2009).

A la vez, la ideología interactúa con el tipo de partidos políticos. Los partidos programáticos de izquierda, es decir, aquellos con una organización interna democrática y una oferta electoral específica frente a los asuntos públicos (Cheeseman y otros 2014), han sido más sensibles a las políticas de igualdad de género que otras combinaciones de ideología y tipo de partido (Blofield, Ewig \& Pisocopo 2017).

Durante los 2000, las políticas de familia en países del Norte global estuvieron menos sujetas a las diferencias ideológicas (Morgan 2006; Fleckenstein \& Lee 2014). La competencia electoral motivó que partidos conservadores buscaran adhesión electoral de madres trabajadoras mediante políticas de familia históricamente asociados a la socialdemocracia (Morgan 2006). La competencia es relacional: no solo importa quiénes promueven las medidas, sino con quiénes se disputan. Por ejemplo, en 2013 el candidato conservador a la presidencia de Chile respaldó extender la licencia por maternidad dado que su contrincante de centro-izquierda lo hacía (Castiglioni 2019). La competencia electoral conllevará cálculos que desdibujaran la importancia de la ideología. 
En América Latina, bajo regímenes presidencialistas las variaciones en la ampliación de las licencias por nacimiento durante la década expansiva en Argentina, Brasil, Chile y Uruguay reflejó la combinación entre iniciativa presidencial y partidos políticos programáticos (Chile, Uruguay) versus no programáticos (Argentina, Brasil) (Blofield \& Touchton 2019). Variaciones entre países requieren examinar el posicionamiento presidencial y las demandas sociales que podrían explicar dicho posicionamiento (Marzonetto 2019). Esperamos que los cambios hayan reflejado un papel activo del Poder Ejecutivo (y concretamente presidencial) en atención a demandas organizadas.

La incidencia pro-ampliación de derechos paternos puede provenir de un tipo de las organizaciones de padres en conflicto con las madres (en adelante OPS). Estas organizaciones disputan que las madres sean entendidas como principales o únicas cuidadoras y demandan más prerrogativas en materia de cuidados (Kaye \& Tolmie 1998; Crowley 2008; León 2020). Al demandar custodias compartidas, estas organizaciones luchan a su vez por una reducción de pensiones alimentarias. Las OPS, son generalmente antifeministas y reaccionan a los avances en la protección de las mujeres en el ámbito doméstico (Chamberlain 2011; Flood 2012).

Por su parte, los mecanismos estatales de protección de las mujeres (como el SERNAM en Chile) han opuesto cambios promovidos por partidos conservadores y buscado proteger a las madres ante separaciones o divorcios (Gustá, Madera \& Caminotti 2017). Por lo tanto, la incidencia pro-derechos paternos provendrá principalmente desde organizaciones de sociedad civil que buscan transformar la regulación estatal, mientras que, aquellos pro-deberes paternos provendrán de demandas feministas, generalmente canalizadas mediante actores estatales.

\section{METODOLOGÍA}

Reconstruimos las iniciativas legislativas asociadas al ejercicio de la paternidad en ausencia de conyugalidad entre enero de 2009 y diciembre de 2018 en tres países comparables debido a alta capacidad estatal, regímenes presidencialistas y organización unitaria, cuya probabilidad de aprobación de legislación nacional es mayor que la de países federales (Tsebelis 2002).

Las fuentes analizadas fueron actas legislativas, comparecencias, mociones y votaciones disponibles en los Congresos. Redujimos la probabilidad de obviar eventos relevantes consultando dos medios de prensa diarios y uno semanal de alta circulación y heterogeneidad ideológica en cada país.

El análisis fue documental. En cada caso examinamos las transformaciones ocurridas respecto a los cuidados y la manutención económica, expresados en la tenencia física de menores y en el pago de las pensiones alimentarias, respectivamente. La reconstrucción de procesos, primero, distinguió iniciativas según prosperaran o no y según su orientación, "pro-derechos" o "pro-deberes" 
paternos; segundo, reconstruyó el respectivo proceso político precisando los respectivos puntos de partida en materia de cuidados y provisión económica; y, tercero, identificó factores de la dinámica política asociados a los respectivos resultados.

La definición de las demandas según fuera "pro-derechos" o "pro-deberes" paternos se realizó en función del contexto en el que tiene lugar el debate político y de políticas en América Latina, el cual está caracterizado por a) una persistente división sexual del trabajo entre responsabilidades económicas principalmente masculinas y responsabilidades cuidadoras principalmente femeninas; b) altos grados de incumplimiento económico paterno. Las demandas "pro-derechos" paternos argumentan que la regulación actual pro-preferencia materna fomenta la persistente división sexual del trabajo y por ello debe cambiarse. Las demandas "pro-deberes" paternos buscan mejorar el grado de cumplimiento paterno en materia de provisión económica, argumentando además decisiones judiciales en escenarios de conflicto parental difícilmente pueden construir corresponsabilidad. Países escandinavos, pioneros en la incorporación de los padres a los cuidados, establecieron la tenencia compartida definida judicialmente en 1981 (Noruega) y 1998 (Suecia), para eliminarla ambos en 2006 por considerarla inviable e indeseable para hijos e hijas (Friðriksdóttir 2014). En su lugar, se reforzó la necesidad de basar las decisiones judiciales en valoraciones caso por caso que promuevan la cooperación parental y protejan a los niños de maltrato (Scott 1992). Algo similar ocurre en Islandia desde 2013 (Friðriksdóttir 2014). Ambos argumentos se identifican y describen en el análisis empírico a continuación.

\section{HALLAZGOS}

El cuadro 1 presenta el número de iniciativas y la orientación de los cambios identificados en cada país. Muestra que Costa Rica y Chile ampliaron los derechos paternos; Uruguay amplió sus deberes. En Chile y Uruguay, durante el mismo período, iniciativas legislativas en la dirección contraria no prosperaron. La ampliación de derechos paternos refirió principalmente a la tenencia o cuidados físicos compartidos. La ampliación de deberes paternos generalmente abordó los mecanismos que aseguran el pago de pensiones alimentarias. 
Cuadro 1. Regulación de la paternidad en Chile, Costa Rica y Uruguay: iniciativas legislativas, 2008-2018

\begin{tabular}{|c|c|c|c|c|c|c|}
\hline \multirow[b]{2}{*}{ Variables } & \multicolumn{2}{|c|}{ Tenencia } & \multicolumn{4}{|c|}{ Manutención económica } \\
\hline & $\begin{array}{l}\text { Chile } \\
\text { (2011) }\end{array}$ & $\begin{array}{l}\text { Uruguay } \\
(2016, \\
2017)\end{array}$ & $\begin{array}{l}\text { Chile } \\
(2018, \\
2019)\end{array}$ & $\begin{array}{c}\text { Uruguay } \\
(2017,2018)\end{array}$ & $\begin{array}{c}\text { C. Rica }{ }^{1 /} \\
(2015,2017 \\
2018 \text { y 2019) }\end{array}$ & $\begin{array}{l}\text { C. Rica } \\
(2015)\end{array}$ \\
\hline \# de iniciativas & 2 & 2 & 8 & 2 & 4 & 1 \\
\hline $\begin{array}{l}\text { Cambios enfocados } \\
\text { en deberes o } \\
\text { derechos paternos }\end{array}$ & $\begin{array}{l}\text { Sí, derechos } \\
\text { paternos } \\
(2011)\end{array}$ & $\begin{array}{c}\text { No, } \\
\text { derechos } \\
\text { paternos }\end{array}$ & $\begin{array}{c}\text { No, } \\
\text { deberes }\end{array}$ & $\begin{array}{l}\text { Sí, deberes } \\
(2017,2018)\end{array}$ & $\begin{array}{c}\text { No, } \\
\text { derechos }\end{array}$ & $\begin{array}{c}\text { Sí, } \\
\text { deberes } \\
(2019)\end{array}$ \\
\hline
\end{tabular}

A continuación, reconstruimos cada caso.

\section{Chile}

En Chile una reforma amplió los derechos paternos en matera de cuidados mientras que múltiples iniciativas que no prosperaron, buscaron garantizar los deberes paternos en materia de manutención económica.

\section{Eliminación de la preferencia materna en el cuidado personal}

Entre 2008 y 2018 el Congreso de Chile discutió dos iniciativas para modificar los cuidados de las/os menores ante separación parental. Hasta entonces, si madre y padre vivían separados, ello le correspondía a la madre, salvo acuerdo parental o causa justificada. Además, los cuidados no podían confiarse al progenitor que, pudiendo, no aportara a la manutención de sus hijos (Cámara de Diputados de Chile 2000: Art. 225).

En 2008 dos diputados de centro-izquierda (Partido por la Democracia) propusieron sustituir la preferencia materna por el cuidado compartido (Cámara de Diputados de Chile 2008). En 2010, con apoyo multipartidario, este proyecto fue refundido con la iniciativa impulsada por la OPS Amor de Papá (Cámara de Diputados de Chile 2010). Además, durante la campaña electoral de 2009, el candidato conservador, Sebastián Piñera, había comprometido atención legislativa del llamado Síndrome de Alineación Parental o SAP (Cámara de Diputados de Chile 2010).

El proceso parlamentario enfrentó posiciones sobre la preferencia materna, el vínculo entre cuidados y manutención económica, y SAP. Sus proponentes buscaban el reparto de los cuidados y la eliminación de obstáculos al contacto paterno con los menores. Amor de Papá y otras tres organizaciones de padres separados denunciaron el SAP como la principal causa de conflicto sobre la cus- 
todia de los hijos (Amor de Papá 2019; Papá Presente 2019; Papás Por Siempre 2019; Filus Pater 2019). Contradiciendo la evidencia, a partir de experiencias y anécdotas, Amor de Papá incidió en el ámbito legislativo señalando la legislación como barrera para los cuidados paternos y demandando que la tenencia se asumiera como compartida aun ante desacuerdo parental² (Cámara de Senadores de Chile 2013).

Contra las reformas, se buscaba participación paterna sin eliminar preferencia materna; garantizar las obligaciones alimentarias; y disputar la mera existencia de la "alienación parental". Desde el Poder Ejecutivo se apoyaba la preferencia materna, salvo casos de obstrucción parental materna (Congreso Nacional de Chile 2011: pág. art. 225). En la Comisión de Familia, legisladores/as conservadores, de UDI y RN, compartieron que el orden natural hacía a las mujeres más idóneas para la crianza. Mantener a la madre como titular del cuidado personal reconocía este orden, daba seguridad a los menores y evitaba incrementar la judicialización (Congreso Nacional de Chile 2011). ${ }^{3}$

Conocida como "Amor de Papá", la ley finalmente aprobada en 2013 por unanimidad, eliminó la preferencia materna (Cámara de Diputados de Chile 2013). Ante desacuerdo, la decisión judicial considera el interés superior del niño, los cuidados previa separación y la actitud de cooperación parental (aludiendo al SAP). La ley también garantiza tiempo de hijos e hijas con quien no conviven normalmente.

En términos de manutención económica, las OPS argumentaron que con la tenencia compartida los padres principalmente hicieran pagos directos a los gastos de los hijos (Congreso Nacional de Chile 2018). Organizaciones de padres separados como Papá Presente argumentaron que se resolvería así la falta de rendición de cuentas materna sobre el uso de los aportes paternos (Congreso Nacional de Chile 2012). Sin embargo, atendiendo planteo del SERNAM, el estar al día con la manutención económica sería un criterio a considerar para definir la tenencia (Cámara de Diputados de Chile 2011: pág. art. 225 bis).

Los proponentes defendieron reiteradamente la inclusión del SAP. La iniciativa de 2008 denunciaba el silencio legal y la ausencia de reproche social ante las madres que lo ejercen (Cámara de Diputados de Chile 2008). Expertos cuestionaron la existencia del síndrome (Congreso Nacional de Chile 2018) y organizaciones feministas lo denunciaron como sexista (Lagos 2011). Como corolario, la Comisión de Familia rechazó unánimemente que el SAP tuviera reconocimiento científico y jurisprudencial (Cámara de Diputados de Chile 2011). La formulación negociada producto del extenso debate vinculó los derechos del progenitor que no vive con sus hijos (art. 229) a las buenas relaciones parentales - en alusión implícita al SAP (art. 225bis). 
La ley entró en vigencia en 2013. Las OPS pronto denunciarían problemas de aplicación de la legislación, en tanto el SERNAM argumentaría que jueces y abogados requerían capacitación y adaptación (La Tercera 2013a) ${ }^{4}$. Cinco años después, Amor de Papá continuaba denunciando problemas de implementación abonados por vacíos legales (Amor de Papá 2018). En 2019 se presentaría la iniciativa "Amor de Papá Más" para retomar la tenencia compartida como regla; la potestad judicial de suspender o modificar la relación con el progenitor alineador; y su sanción con pena de reclusión (Cámara de Diputados de Chile 2019: págs. Arts. 225, 229, 327).

\section{Proliferación de iniciativas legislativas para garantizar pensiones alimentarias}

Varias iniciativas legislativas buscaron mejorar el cumplimiento de las pensiones alimentarias. Aunque en Chile el incumplimiento es el menor de los tres países examinados, mientras se debatía la tenencia compartida en 2011, el Poder Judicial reportaba más del $60 \%$ de pensiones alimentarias adeudadas (La Tercera 2013b). Aunque objetaban varios aspectos de la legislación vigente, las OPS estuvieron ausentes del debate legislativo.

Desde 2006, una reforma legal había introducido la suspensión de licencias de conducir, retención en la devolución anual de impuestos y facultad de allanamiento y apremio a deudores alimentarios (Cámara de Diputados de Chile 2007). La actividad legislativa para mejorar el pago de pensiones alimentarias reapareció en 2015, de la mano de iniciativas punitivas y de avergonzamiento social.

Entre 2015 y julio de 2019, la Comisión de Familia en el Congreso tramitó ocho proyectos para garantizar el pago de pensiones alimenticias, cada uno respaldado por legisladores/as del mismo partido (RN, FREVS y seis de Nueva Mayoría). Propusieron crear un registro nacional, eliminar la prescripción, habilitar pago retroactivo de gastos médicos, sanciones no judiciales y tipificación de deudas como maltrato infantil. Adicionalmente, legisladores de la UDI propusieron crear un fondo nacional para pagar pensiones alimentarias a familias vulnerables. La mayoría de estos proyectos fueron refundidos con otras iniciativas. A marzo de 2019 ninguna de las iniciativas había sido aprobada.

\section{Uruguay}

En Uruguay una reforma amplió los deberes paternos y dos iniciativas buscaron ampliar los derechos paternos.

Durante el período se discutió el cuidado personal en parejas del mismo sexo y la ley de Acuerdo de Unión Civil; en 2015 ocurrió el primer fallo judicial de tuición a la expareja del mismo sexo de una mamá fallecida (The Clinic 2015). 


\section{Iniciativa estatal concita amplios acuerdos para garantizar pensiones alimentarias}

Las dos reformas que buscaron mejorar el cumplimiento de las pensiones alimentarias de padres asalariados y no asalariados, respectivamente, fueron producto de procesos legislativos cortos y unánimemente apoyados.

Desde 2006 existía un registro de deudores alimentarios promovido por la multipartidaria Bancada Bicameral Femenina (BBF) y apoyado por el Poder Judicial y organizaciones de mujeres e infancia (Parlamento del Uruguay 2005). Aunque ingresar al registro impedía contrataciones públicas, cuando el obligado alimentario no aportaba información o atrasaba pagos, las madres debían investigar, recolectar información e informar al juzgado (El Observador 2019). En retrospectiva, para las madres el registro había implicado tiempo, asesoramiento legal, y dinero para gestiones y cuidados de los hijos (Cámara de Senadores de Uruguay 2016a). Además, en 2012, 60\% de menores de edad con padre no residente continuaba sin pensión alimentaria (Cabella y otros 2015).

En junio de 2016, el Poder Ejecutivo envió al Parlamento la creación del Registro Nacional de Obligados, ya no deudores, Alimentarios (RENOA). El juzgado proporcionaría el monto establecido al empleador y al ente responsable del sistema previsional, el Banco de Previsión Social (BPS). Solo seis meses después, el RENOA era ley con el apoyo unánime en ambas cámaras (Parlamento del Uruguay 2017). Desde la vigencia de la ley en febrero de 2017, la carga de la prueba respecto al incumplimiento pasó de las madres al Estado (El Observador 2019), ya que el BPS ordena la retención de la transferencia a las empresas relacionadas con la persona obligada (como trabajadora, titular o socia) y actualiza los cambios posteriores (Mareco 2018).

El pronto y amplio apoyo fue producto de acciones simultáneas. En junio de 2016, enmarcada en la campaña "Ni una menos" contra la violencia de género, diputados del partido oficialista Frente Amplio (FA) promovieron una consulta al BPS sobre acciones que mejoraran el cumplimiento de las pensiones alimentaria (Cámara de Representantes del Uruguay 2016: Art. 114-5). Paralelamente, el grupo técnico de Género y Violencia del BPS proponía crear el RENOA. Entre agosto y diciembre de 2016 la propuesta fue avalada por la gerencia del BPS, consultada a la Corte Suprema de Justicia, mejorada por el Ministerio de Trabajo, y respaldada por el Consejo de Ministros (Pandiani 2019).

En el Parlamento, en diciembre de 2016, la BBF comunicaba públicamente que la creación de este registro sería una de sus tres prioridades durante 2017, junto al combate a la violencia de género y la participación política paritaria (Bancada Bicameral Femenina 2016). En 2017, legisladores de todos los partidos políticos aprobaron el proyecto en Diputados y en Senadores (Cámara de Senadores del Uruguay 2016c).

Para corregir el alto grado de incumplimiento de los aportes alimentarios, desde el partido Independiente se propuso ampliar la legislación al patrimonio y a 
los trabajadores independientes o en condición irregular que hasta ese momento podían fácilmente esconder ingresos (Bucheli \& Cabella 2005). Con la creación de una Declaración Jurada Obligatoria de Haberes e Ingresos, omisiones en la declaración jurada constituyen un delito penal análogo a la evasión fiscal (Parlamento del Uruguay 2019).

\section{Organizaciones de padres separados militan por la tenencia compartida}

Desde 1994 la legislación uruguaya prevé la tenencia física de mutuo acuerdo entre padre y madre (Parlamento del Uruguay 1994). El Código de la Niñez y la Adolescencia de 2004 reiteró esta regulación (Parlamento del Uruguay 2004: Art. 34). En ausencia de acuerdo parental, se prefiere a la madre los dos primeros años de vida, seguido del análisis judicial caso por caso.

Durante este período, la iniciativa para introducir cambios en el derecho de familia estuvo en manos de OPS. Las organizaciones más visibles fueron Stop Abuso (SA) y Todo por Nuestros Hijos (TPNH). Desde 2013, SA denunció los impedimentos del vínculo parental y el maltrato infantil (El País 2016). Fundada en 2013, TPNH cada Día del Padre denuncia frente a la Corte Suprema de Justicia la inequidad de los procesos de divorcio (El País 2016; Primera Hora 2019). Consideran que padres cuidadores se enfrentan a madres inescrupulosas, ${ }^{5}$ jueces que aplican mal la ley y legisladores que se niegan a cambiarla (Balderrín 2017).

En 2015 mediante una propuesta de "tiempo equitativo", SA buscó darle mayor tiempo de contacto a los padres que no conviven con sus hijos/as (Cámara de Representantes del Uruguay 2015b: Art. 3). TPNH inicialmente apoyó la iniciativa como una propuesta inocua pero que buscaba votos del mayoritario FA (El País 2018). Un año después, constatando que el FA no apoyaría la propuesta, TPNH a través del entonces senador Lacalle Pou, ahora presidente de la República, propuso la tenencia compartida aun mediando desacuerdo parental y denuncias sin sentencia en contra de un progenitor (Cámara de Senadores del Uruguay 2016). TPNH señaló que la legislación vigente no prohibía pero tampoco promovía la tenencia compartida, y que esta reduciría las demandas alimentarias y de visitas (Canal 4 2018). Apeló a países que la han implementado - como Chile - y a estudios científicos que muestran sus beneficios.

Las iniciativas fueron canalizadas a través del Partido Nacional que ya en 2015, había propuesto regular la alienación parental (Cámara de Representantes del Uruguay 2015a). Al darse inicio en Comisión al trámite legislativo sobre tiempo equitativo ${ }^{6}$, voceros de $S A$ enfatizaron la alienación parental como maltrato

Por ejemplo, en febrero de 2019 la organización exigió a la Intendencia de Montevideo derogar sus "leyes feministas" y denunció que se recibiera a organizaciones feministas, pero no de padres (Balderrín, 2017). Comisión de Constitución integrada por legisladoras/es del FA (6), Partido Nacional (3), Partido Independiente (1) y Partido Colorado (1). 
infantil y denunciaron inacción ante las madres maltratadoras, vinculando así alienación parental y tiempo equitativo (Cámara de Representantes del Uruguay 2018a).

Entidades públicas especializadas apoyaron el concepto de tiempo equitativo, consideraron que ya existía y dudaron sobre una aplicación estricta del criterio. En noviembre de 2018, el diputado proponente buscó ampliar apoyos con un texto más general que indicara que los jueces deberían procurar que el tiempo de contacto posibilitara una relación equitativa de los hijos con padres y madres (Cámara de Representantes del Uruguay 2018b). Sin embargo, careció del apoyo del FA y del PI y se postergó su tratamiento.

La iniciativa del senador Lacalle explícitamente reconoció la autoría de TPNH y el papel del Partido Nacional como intermediario entre la sociedad civil y el parlamento (Cámara de Senadores del Uruguay 2016: Art. 3). La iniciativa careció de apoyo de la mayoría del FA y de interés de otros partidos. En 2017, senadores del FA argumentaron que no apoyarían al proyecto porque la tenencia compartida ya existía (Cámara de Representantes del Uruguay 2019).

\section{Costa Rica}

Allí las iniciativas, prosperaran o no, buscaron ampliar los derechos paternos.

\section{Proliferación de acciones legislativas y judiciales contra normas injustas}

Costa Rica tiene el mayor incumplimiento de obligaciones alimentarias de los tres países analizados. Excepto el Código Procesal de Familia, las iniciativas legislativas y judiciales reflejaron el accionar de las OPS y de unos pocos legisladores. Padres deudores alimentarios buscaron flexibilizar el uso de la cárcel, las condiciones para salir del país, y, en menor medida, regular la "alienación parental". Paralelamente, tanto desde el Poder Judicial como desde el Ejecutivo, se defendió la normativa vigente.

Dos fueron las OPS clave en esta materia: la Fundación Instituto de Apoyo al Hombre (FUNDIAPHO) y la Asociación Igualdad de Derechos para los Hombres (AIDH) ambas creadas en el 2013. Estas organizaciones recurrentemente cuestionaron la normativa porque "Nosotros, los hombres, vamos a la cárcel por ser pobres; no por ser delincuentes, sino porque no tenemos plata para pagar la ridiculez de cifra que nos imponen como pensión" (La Nación 2016). Paralelemente, incidieron políticamente para reducir pensiones alimentarias que consideran abusivas y flexibilizar sanciones ante incumplimiento (Asamblea Legislativa de Costa Rica 2017a).

Hasta muy recientemente sus propuestas carecieron de apoyo judicial o legislativo. Por ejemplo, las OPS fracasaron en eliminar los ajustes automáticos de 
las pensiones alimentarias porque el mecanismo buscaba acompañar el costo de vida (Sala Constitucional 2013). Tampoco prosperaron acciones de inconstitucionalidad y recursos de amparo contra el pago escolar anual (Sala Constitucional 2015a; Sala Constitucional 2016). El poder judicial falló además en contra de eliminar el equivalente a un año de aportes alimentarios o presentar autorización de la madre como requisito para salir del país (Asamblea Legislativa de Costa Rica 1996; Sala Constitucional 2014; Sala Constitucional 2015b)

Paralelamente, una recurrente presentación de proyectos de ley que reformaran la normativa vigente obtuvo escaso apoyo en el Congreso. En 2015 el conservador partido PASE planteaba que en la cárcel había trescientos deudores alimentarios sin empleo, sin ver a sus hijos/as, y costándole dinero al Estado (Diario Extra 2015; La Prensa Libre 2016b). Aunque no prosperara, este proyecto resumió la agenda de las OPS: que la solicitud de pensiones alimentarias estipulara claramente el destino de los fondos (Asamblea Legislativa de Costa Rica 2015a); que el deudor no tuviera uno sino tres meses para encontrar empleo antes del apremio físico (Diario Extra 2016); que existiera cárcel nocturna para que el deudor trabajara y viera a sus hijos/as durante el día (Diario Extra 2015; Asamblea Legislativa de Costa Rica 2015a); que los deudores pudieran usar sus propiedades como garantía para salir del país (Asamblea Legislativa de Costa Rica 2015a); y que el desprestigiar al deudor, realizar falsas acusaciones o dificultar su contacto con los hijos ampliaría los derechos del deudor alimentario (Asamblea Legislativa de Costa Rica 2015a).

En 2017 con el apoyo de partidos de centro, centro-derecha y derecha (PAC, PLN, ML y PASE) la AIDH propuso tablas orientativas que redujeran la discrecionalidad judicial - y los conflictos parentales - en la fijación de los montos de las pensiones alimentarias (Noticia Monumental 2017; La Nación 2017a). Las sumas se establecerían con base en los ingresos de los padres e información oficial del costo de vida (Crhoy.com 2017). En 2018 otro diputado conservador (PRN), retomó la propuesta (Asamblea Legislativa de Costa Rica 2018c). Aunque los impulsores argumentaban tener apoyo del Ministerio de Justicia (Noticia Monumental 2017), operadores de justicia cuestionaron las tablas por excluir rubros importantes como educación y salud, ignorar las particularidades de cada situación y erosionar la independencia de cada juez (La Nación 2017b). Ninguna de las iniciativas avanzó como tampoco prosperó en 2019 la propuesta de la AIDH para que el padre alimentante pudiera limitar mal manejo materno de la pensión alimentaria solicitando pruebas de su uso (Asamblea Legislativa de Costa Rica 2019a).

Como medidas novedosas para garantizar el pago, en 2018 las OPS promovieron crear un seguro que cubriera el pago completo de manutención económica durante tres meses ante imprevistos como el despido (Asamblea Legislativa de Costa Rica 2018b; Diario Extra 2018). Se financiaría entre deudores, adeudados y Estado y evitaría encarcelamiento, desempleo y consiguiente afectación económica de los menores (Diario Extra 2018). Auque ingresó a comisión en 2018, no ha prosperado. 


\section{Flexibilización de sanciones y mecanismos frente a insolvencia económica}

En 2015 el Poder Ejecutivo promovió un código procesal de toda la materia en familia, en cuenta las pensiones alimentarias. La propuesta había sido elaborada por el Poder Judicial desde 2008 (Asamblea Legislativa de Costa Rica 2015b) y fue aprobado por unanimidad en el Congreso en junio de 2019 (Asamblea Legislativa de Costa Rica 2019b). ${ }^{7}$

En materia de pensiones alimentarias cambiaba algunas medidas y mantenía otras. Entre los cambios, el proyecto demoraba y acotaba la definición judicial de una pensión alimentaria provisoria; habilitaba la consulta judicial de ingresos del obligado alimentario ante la seguridad social; actualizaba los montos según costo de vida en lugar de aumentos salariales o de salario mínimo, y definía judicialmente los gastos educativos (Asamblea Legislativa de Costa Rica 2015b: Arts. 260, 261). A la vez, se mantenía la retención de ingresos y la restricción migratoria vigente: salvo autorización de la madre, previa salida del país, los alimentantes debían depositar el monto equivalente a un año de manutención (Asamblea Legislativa de Costa Rica, 1996; Asamblea Legislativa de Costa Rica, 2015b). Se mantenía la pena de cárcel por hasta seis meses frente a incumplimiento, aunque se habilitaba el pago en cuotas del monto adeudado (Asamblea Legislativa de Costa Rica 1996: Art. 25).

En el Congreso la iniciativa sufrió modificaciones sustantivas avaladas por el Poder Ejecutivo. En defensa de los mecanismos existentes para garantizar los alimentos incidieron el Instituto Nacional de las Mujeres (INAMU) y la Defensoría de los Habitantes. En defensa de los obligados alimentarios y de limitar el uso de la cárcel, participaron FUNDIAPHO y la AIDH (Crhoy.com 2017b).

El Congreso introdujo tres cambios sustantivos consultados con el Poder Judicial y apoyada por todos los partidos (Asamblea Legislativa de Costa Rica 2017b). Primero, se refirió explícitamente a la organización de los cuidados y la manutención económica en casos de separación o divorcio. Las partes deberían indicar organización de la custodia y obligación alimentaria hacia hijos menores de edad (art. 48). Hasta entonces el Código de Familia promovía la manutención económica como una responsabilidad masculina - y de la mujer "en la medida de sus posibilidades" (Asamblea Legislativa de Costa Rica 1974: Art. 35).

Segundo, se introdujo la gradualidad de la cárcel: hasta dos, cuatro y seis meses del primer al tercer incumplimiento, respectivamente (Asamblea Legislativa de Costa Rica 2019). Si carecía de recusos, el deudor tendría para pagar hasta un mes, prorrogable a dos. Además, el juez podría reducir el apremio diario, de veinticuatro a ocho horas hasta por seis meses cuando se buscara trabajo

Tanto en primer como en segundo debate (abril 2018 y junio 2019), fue apoyado por 40 diputados/as presentes del total de 57 (Asamblea Legislativa de Costa Rica 2019). 
(Asamblea Legislativa de Costa Rica 2018: Art. 284). Esta propuesta de AIDH fue respaldada por diputados conservadores (PASE y PLN) argumentando que el apremio nocturno facilitaría honrar deudas alimentarias.

También se excluyó del apremio físico a menores de edad y personas adultas mayores de 75 años (Asamblea Legislativa de Costa Rica 2015b). Un fallo de 2016 había declarado inconstitucional encarcelar menores de edad. Tanto diputados de izquierda (FA) como de centro-derecha (PLN) buscaron acotar el apremio (Asamblea Legislativa de Costa Rica, 2016). Desde la AIDH se defendió la edad máxima vigente como un logro humanitario (Crhoy.com 2018) y junto con FUNDIAPHO, opuso el descenso de la edad mínima para proteger el derecho a estudiar (La Prensa Libre 2016a; Crhoy.com 2017).

Tercero, se creó un Fondo de Pensiones Alimentarias para atender deudas asociadas a desempleo, enfermedad o accidentes (Asamblea Legislativa de Costa Rica 2016). Financiada con 15\% de depósitos judiciales e intereses de procesos judiciales, esta medida vinculó legislación en familia y protección social (Asamblea Legislativa de Costa Rica 2015b).

La Defensoría y el INAMU cuestionaron la falta de regulación de la pensión provisional que garantiza el derecho humano a los alimentos (Informa-tico 2018; INAMU 2019). El tema se resolvió estableciendo que luego de diez días sin conciliación, se definiría pensión provisional en máximo 24 horas (Asamblea Legislativa de Costa Rica 2018; 2019). La Defensoría opuso cambios en el apremio corporal en tanto único instrumento efectivo disponible para garantizar pagos alimentarios. Además, consideró riesgoso que fuera un juez y no un médico quien definiera cuándo el apremio físico empeoraría una condición de salud (Asamblea Legislativa de Costa Rica 2019b). Sin embargo, el Poder Judicial defendió los cambios argumentando que mejorarían el cumplimiento del pago alimentario (Sala Constitucional 2018).

En 2019, un acuerdo interpartidario del oficialista PAC y del mayoritario PLN conllevó la aprobación del Código Procesal de Familia (El País.cr 2019). La controversia, sin embargo, continuó luego de aprobado. Por ejemplo, el INAMU pidió a la Asamblea Legislativa que antes de su entrada en vigor en octubre del 2020, se introdujeran criterios claros respecto al uso del tiempo reducido de prisión de forma nocturna. Asimismo, denunció la poca claridad sobre cambios que amenazan los derechos de la niñez y continúan responsabilizando a las mujeres por su cuido y manutención (INAMU 2019).

\section{ANÁLISIS COMPARADO}

La ampliación de derechos paternos fue promovida por las organizaciones de padres separados. Estas recurrieron a partidos políticos conservadores para mejorar su estatus legal en materia de tenencia de hijos/as (Chile, Uruguay) y/o de flexibilizar las sanciones cuando incumplen obligaciones alimentarias 
(Costa Rica). Buscaron generalmente para ello eliminar la preferencia materna respecto a la custodia de hijos e hijas menores de edad, ganar terreno en las disputas judiciales y obtener mayor control sobre madres e hijos/as.

Aunque los partidos conservadores son generalmente maternalistas y favorecen la preferencia materna en la crianza, en nombre del vínculo familiar, apoyaron las demandas de las OPS tanto respecto a tenencia como a la llamada alienación parental (Chile, Costa Rica, Uruguay). La defensa de las madres estuvo en manos de instituciones estatales como los mecanismos de promoción de la igualdad de las mujeres (SERNAM en Chile, INAMU Costa Rica) $\mathrm{y}$, en otros, órganos de defensa ciudadana (Costa Rica) o de seguridad social (Uruguay) con presencia de mujeres con perspectiva de género respecto a los conflictos implicados en la tenencia física y en la manutención económica de niños y niñas.

Los partidos progresistas programáticos, denunciaron la violencia patrimonial como expresión de la desigualdad de género y promovieron medidas de afirmación positiva hacia las madres y sus hijos/as. Ilustra esta afirmación la consistencia programática del FA uruguayo, no así de los partidos integrantes de la CPD y de la Nueva Mayoría Chilena que variaron su postura entre asuntos y proyectos.

La interacción entre actores de sociedad civil (padres separados en conflicto con las madres) o estatales (mecanismos de promoción de la mujer) y legisladores/as afines, se expresó en propuestas, aunque no en cambios efectivos. Solo fueron aprobadas medidas respaldadas por el Poder Ejecutivo: como muestra el cuadro 2, los tres proyectos exitosos fueron iniciativas de los respectivos presidentes (Piñera, Vázquez, Solís / Alvarado), hubiera habido o no una ajustada competencia electoral (Chile y Uruguay, respectivamente).

En Chile, dos iniciativas legislativas pro-ampliación de derechos paternos en 2008 y 2011 bajo las administraciones de Bachelet (centro-izquierda) y Piñera (derecha), respectivamente, indican que la afinidad entre OPS congresistas, garantizó reformas legislativas, solo si contaban con el apoyo del Poder Ejecutivo (véase cuadro 2). Concretamente, una misma iniciativa legislativa prosperó solo cuando tuvo el apoyo del presidente Piñera. 
Cuadro 2. Regulación de la paternidad en escenario de conflicto parental: iniciativas legislativas en Chile, Costa Rica y Uruguay: 2008-2018

\begin{tabular}{|c|c|c|c|c|c|c|}
\hline & \multicolumn{3}{|c|}{ Aprobados } & \multicolumn{3}{|c|}{ No aprobados } \\
\hline & $\begin{array}{l}\text { Chile } \\
(2011)\end{array}$ & $\begin{array}{c}\text { Uruguay } \\
(2017,2018)\end{array}$ & $\begin{array}{c}\text { Costa Rica } \\
(2019)\end{array}$ & $\begin{array}{c}\text { Chile (2018, } \\
\text { 2019) }\end{array}$ & $\begin{array}{c}\text { Uruguay } \\
(2015,2016)\end{array}$ & Costa Rica \\
\hline Orientación & $\begin{array}{l}+ \text { Derechos } \\
\text { paternos }\end{array}$ & $\begin{array}{l}\text { + Deberes } \\
\text { paternos }\end{array}$ & $\begin{array}{l}+ \text { Derechos } \\
\text { paternos }\end{array}$ & $\begin{array}{l}\text { + Deberes } \\
\text { paternos }\end{array}$ & $\begin{array}{l}+ \text { Derechos } \\
\text { paternos }\end{array}$ & $\begin{array}{l}\text { + Derechos } \\
\text { paternos }\end{array}$ \\
\hline Iniciativa & OPS & BBF y BPS & OPS & Legisladores & OPS & OPS \\
\hline $\begin{array}{l}\text { Respaldo Poder } \\
\text { Ejecutivo }\end{array}$ & $\mathrm{Si}$ & Sí & Sí & No & No & No \\
\hline $\begin{array}{l}\text { Ideología del } \\
\text { Poder Ejecutivo }\end{array}$ & $\begin{array}{l}\text { Derecha } \\
\text { (Piñera 1) }\end{array}$ & $\begin{array}{l}\text { Izquierda } \\
\text { (Vázquez) }\end{array}$ & $\begin{array}{l}\text { Centro- } \\
\text { izquierda } \\
\text { (Solís, } \\
\text { Alvarado) }\end{array}$ & $\begin{array}{l}\text { Derecha } \\
\text { (Piñera 2) }\end{array}$ & $\begin{array}{l}\text { Izquierda } \\
\text { (Mujica, } \\
\text { Vázquez) }\end{array}$ & $\begin{array}{l}\text { Centro- } \\
\text { izquierda } \\
\text { (Alvarado) }\end{array}$ \\
\hline
\end{tabular}

Fuente: Elaboración propia.

En suma, el período examinado fue intenso en conflictos y construcción de acuerdos en torno a la regulación estatal de la paternidad. Los respectivos procesos políticos reflejaron la participación de las OPS como un actor político nuevo, promotor de cambios profundos en el derecho de familia y, en particular, en los deberes paternos. Para promover su agenda buscaron el apoyo de políticos conservadores, tanto de presidentes (Chile) como de legisladores cuando estos partidos políticos estaban en la oposición (Costa Rica, Uruguay). Las iniciativas exitosas contaron todas con apoyo del Ejecutivo. Paralelamente, desde una perspectiva de defensa de los derechos de las madres y de sus hijos / as, actores estatales buscaron ampliar el cumplimiento de deberes paternos hacia las madres y sus hijos/as en materia económica.

\section{CONCLUSIONES}

Este artículo da cuenta de transformaciones recientes en un área de intervención estatal escasamente estudiada y altamente relevante para la asignación de los recursos de tiempo y dinero en las familias. Esta área es relevante también en términos electorales y para el futuro de las políticas con perspectiva de género que busquen transformar las relaciones de poder entre hombres y mujeres en la región.

A pesar de continuar siendo uno de los Congresos con menor participación femenina (Caminotti 2021) ${ }^{8}$, Uruguay se destaca por sus cambios favorables a la igualdad de género en materia parental. A la vez, a partir de los tres casos examinados la evidencia empírica reafirma el argumento de Pribble (2013) de que la capacidad predictiva de la ideología depende del carácter programático de los partidos políticos. Estos hallazgos son consistentes con la evidencia a nivel

8 Durante el período examinado esa proporción fue de 15\% entre 2010 y 2014 y de 20\% en el período 20142019, comparable a lo ocurrido en Chile y muy por debajo del casi 30\% en Costa Rica. 
global, la cual muestra que no son cualesquiera partidos políticos de izquierda los que dan prioridad a los asuntos de género (McBride Stetson \& Mazur 1995). En Uruguay una izquierda programática promovió acciones afirmativas, tanto en materia de cuidados como de manutención económica. Dado el punto de partida de Uruguay adonde en casos de conflicto parental la legislación no era maternalista, la postura de la izquierda fue mantener este marco jurídico de preferencia materna acotado a la vez que promovió cambios enfocados en garantizar los deberes económicos paternos.

En los tres países las demandas feministas quedaron principalmente expresadas en el papel de las agencias estatales de defensa de los derechos de las mujeres. Ello es coherente con la literatura institucionalista feminista que muestra el papel de estas agencias con independencia de la ideología de los gobiernos (McBride \& Mazur 2010). Esta literatura documenta además la importancia de considerar estas capacidades estatales en su interacción con estructuras participativas feministas de sociedad civil (Gustá, Madera, \& Caminotti 2017). Futuras investigaciones deberían vincular más fuertemente el análisis del derecho de familia como parte de los estudios sobre regímenes de bienestar y social en América Latina. Además, debería integrar a las OPS como actor político y profundizar en su análisis a la luz del estudio de las redes de asuntos (Htun \& Weldon 2010). La literatura señala que la participación política de las mujeres puede resultar en un mayor impulso a agendas "pro mujeres", cuando los electorados están conformados por mujeres movilizadas sobre la base del género que participan en definir cuáles son los intereses de las mujeres, presionan porque legisladoras y presidentas los articulen (Tobar Ríos 2008; Reyes 2018). En este caso se trataría de valorar el peso relativo que redes de asuntos, conservadoras y feministas, tuvieron en liderar unas transformaciones y en vetar otras.

Producto de las victorias obtenidas, es de esperar que las OPS profundicen su quehacer político, promoviendo mayores cambios en la regulación estatal de la paternidad. Como actor político emergente, las OPS cuestionan la perspectiva de las madres defendida desde el Estado. Es de esperar que la disputa por el apoyo de los Poderes Ejecutivos se profundice, con los consecuentes riesgos respecto a los instrumentos de política que protegen los derechos económicos y parentales maternos.

\section{BIBLIOGRAFÍA}

Amor de Papá. 2018, s.f. "El por qué de la ley Amor de Papá Más." Recuperado el 12 de septiembre de 2019 de http://amorporloshijos.org/david-abuhadba/una-nuevapropuesta-el-porque-de-la-ley-amor-de-papa-mas/.

Amor de Papá. 2019, s.f. “¿Qué es el Síndrome de Alienación Parental?” Recuperado el 12 de setiembre de 2019 de http:/ /www.amordepapa.org/que-es-el-sindrome-de-alienacion-parental-2/

Asamblea Legislativa de Costa Rica. 1974, 05 de agosto. "Ley № 5476 Código de Familia." Recuperado el 16 de enero de 2020 de http://www.pgrweb.go.cr/scij/Busqueda/ Normativa/Normas/nrm_texto_completo.aspx?nValor1=1\&nValor2=970. 
Asamblea Legislativa de Costa Rica. 1996, 19 de diciembre. "Ley № 7654 Pensiones Alimentarias". Recuperado el 9 de noviembre de 2019 de http://www.pgrweb.go.cr/scij/ Busqueda/Normativa/Normas/nrm_texto_completo.aspx?param1=NRTC\&nValor1=1\&nValor2=41692\&strTipM=TC.

Asamblea Legislativa de Costa Rica. 2015a, 16 de marzo. "Expediente Legislativo № 19.501 Reforma a los artículos 14, 17 inciso d), 21, 22, 24, 31 y creación de los artículos 24 bis, 28 bis Y 31 bis a la ley $N^{\circ} 7654$, Ley de Pensiones Alimentarias del 19 de diciembre de 1996.". Recuperado el 7 de noviembre de 2019 de http://www.asamblea.go.cr/sd/ SiteAssets/Lists/Consultas\%20Biblioteca/EditForm/Proyecto-19501.pdf

Asamblea Legislativa de Costa Rica. 2015b, 20 de enero de 2015. “Expediente Legislativo N $^{\circ}$ 19.455 Código Procesal de Familia." Recuperado el 26 de octubre de 2019 de http:// www.asamblea.go.cr/SitePages/Inicio.aspx.

Asamblea Legislativa de Costa Rica. 2016, 27 de abril de 2016. "Acta de la sesión ordinaria N. 36 Comisión de Asuntos Jurídicos". Recuperado el 10 de enero de 2020 de http:/ / www.asamblea.go.cr/SitePages/Inicio.aspx.

Asamblea Legislativa de Costa Rica. 2017b, 25 de octubre. “Acta de la sesión ordinaria $\mathrm{N}^{\circ} 4$ Comisión Permanente de Asuntos Jurídicos" Recuperado el 25 de enero de 2020

Asamblea Legislativa de Costa Rica. 2017a, 5 de julio. "Criterio sobre el Expediente Legislativo N 19.455 emitido por el Foro de Familia." Recuperado el 31 de julio de 2019 de http://www.asamblea.go.cr/.

Asamblea Legislativa de Costa Rica. 2018a, 5 de abril. "Expediente Legislativo N. ${ }^{\circ} 19.455$ Código Procesal de Familia. San José, Costa Rica." Recuperado el 11 de enero de 2020 de http:/ / www.asamblea.go.cr/.

Asamblea Legislativa de Costa Rica. 2018b, 23 de julio. “Expediente Legislativo N²0.866 Ley de Creación de Seguro Obligatorio de Pensiones Alimentarias (S.O.P.A.)" Recuperado el 31 de octubre de 2019 de http:/ / www.asamblea.go.cr/.

Asamblea Legislativa de Costa Rica. 2018c, 14 de noviembre. "Expediente Legislativo $\mathrm{N}^{\circ}$ 21.092 de uso de tablas orientadoras para la fijación de cuotas alimentarias provisionales." Recuperado el 31 de octubre de 2019 de http:/ / www.asamblea.go.cr/.

Asamblea Legislativa de Costa Rica. 2019, 9 de enero. “Expediente Legislativo No 21.206 Reforma al artículo 171 del Código de Familia, Ley 5476, para tutelar el interés superior de la persona menor de edad beneficiaria de una pensión alimentaria." Recuperado el 9 de enero de 2020 de http:/ / www.asamblea.go.cr/SitePages/Inicio.aspx.

Asamblea Legislativa de Costa Rica. 2019, 19 de junio. “Expediente Legislativo No 19.455 Código Procesal de Familia (Redacción Final)". Recuperado el 11 de enero de 2020, de http:/ /www.asamblea.go.cr/SitePages/Inicio.aspx.

Balderrín, Valentín. 2017, s.f. "La solidaridad en la organización Todo por Nuestros Hijos Ya : entre la racionalidad comunicativa y la autoridad de lo sacro." Recuperado el 17 de septiembre de 2019 de https://www.colibri.udelar.edu.uy/jspui/handle/20.500.12008/17257.

Bancada Bicameral Femenina. 2016, 21 de diciembre de 2016. "Bancada Bicameral Femenina impulsa proyectos de ley". Recuperado el 5 de diciembre de 2019 de https:/ / parlamento.gub.uy/noticiasyeventos/noticias/node/86697.

Birn, Anne, Emanuelle. 2012. “Uruguay's Child's Rights Approach to Health: What Role for Civil Registration?." Proceedings of the British Academy 182: 415-447.

Bliss, Katherine. 1999. "Paternity tests: fatherhood on trial in Mexico's Revolution of the family." Journal of Family History 24(3): 330-350.

Blofield, Merike y Juliana Martínez Franzoni. 2014. “Trabajo, familia y cambios en la política pública en América Latina: equidad, maternalismo y corresponsabibilidad." Revista CEPAL (114): 108-125.

Blofield, Merike y Michael Touchton. 2019. "Moving away from maternalism? The politics of parental leave reforms in Latin America." Comparative Politics 53(1): 1-24.

Blofield, Merike., Christina Ewig y Jennifer Pisocopo. 2017. “The Reactive Left: Gender Equality and the Pink Tide in Latin America." Social Politics 24(4): 345-369. 
Bucheli, Marisa y Wanda Cabella. 2009. “El Incumplimiento en el Pago de las Pensiones Alimenticias, el Bienestar de los Hogares y el Contexto Legal Vigente en Uruguay." Revista Latinoamericana de Población 3(4-5): 123-142.

Buchelli, Marisa y Andrea Vigorito. 2017. "Separation, child-support and well-being in Uruguay." Recuperado el 25 de septiembre de https://www.colibri.udelar.edu.uy/jspui/handle/20.500.12008/18995.

Cabella, Wanda., Mathías Nathan, Peter Fitermann, Andrea Vigorito, Mariana Zerpa y Marisa Buchelli. 2015. “Cambio familiar y bienestar de las mujeres y los niños en Montevideo y el área metropolitana : una perspectiva longitudinal." Recuperado el 28 de septiembre de 2019 de https:/ / www.colibri.udelar.edu.uy/jspui/handle/20.500.12008/7593.

Cámara de Diputados de Chile. 2000, 30 de mayo. “Ley N²1.171 Código Civil." Recuperado el 30 de Enero de 2020 de https:/ / www.camara.cl.

Cámara de Diputados de Chile. 2007, 9 de enero de 2007. “Ley N 20.152 Introduce diversas modificaciones a la Ley $\mathrm{N}^{\circ} 14.908$, sobre abandono de familia y pago de pensiones alimenticias." Recuperado el 3 de Enero de 2020 de https:/ / www.camara.cl.

Cámara de Diputados de Chile. 2008, s.f. "Ley N 20.680 Hitos de tramitación boletín 591718." Recuperado el 30 de julio de 2019 de https://obtienearchivo.bcn.cl/obtienearchivo?id=recursoslegales $/ 10221.3 / 44153 / 7 /$ HL20680.pdf.

Cámara de Diputados de Chile. 2010, 29 de junio. "Boletín № 7007-18 Introduce modificaciones en el Código Civil, en relación al cuidado personal de los hijos." Recuperado el 27 de septiembre de 2019 de https: / / www.camara.cl.

Cámara de Diputados de Chile. 2011, 8 de noviembre. "Historia de la Ley N ${ }^{\circ} 20.680$ Primer Trámite Constitucional Informe de la Comisión de Familia en Sesión $N^{\circ} 35 . "$ Recuperado el 11 de enero de 2020 de https:/ /obtienearchivo.bcn.cl/obtienearchivo?id=recursoslegales/10221.3/44153/7/HL20680.pdf.

Cámara de Diputados de Chile. 2013, 21 de junio. “Ley N 20.680 Introduce modificaciones al Código Civil y a otros cuerpos legales, con el objeto de proteger la integridad del menor en caso de que sus padres vivan separados." Recuperado el 30 de enero de 2019 de https://www.bcn.cl/leychile/navegar?idNorma=1052090.

Cámara de Diputados de Chile. 2019, 19 de junio. “Boletín N 1217-18 Modifica el Código Civil, en materia de cuidado personal compartido de los hijos, y el Código Penal, para sancionar el entorpecimiento de dicho régimen o la imputación falsa o maliciosa de delitos entre padre y madre." Recuperado el 30 de julio de 2019 de https: / www. camara.cl/verDoc.aspx?prmTipo=SIAL\&prmID=48958\&formato=pdf

Cámara de Representantes del Uruguay. 2015a, 8 de julio. “Carpeta N 297 Proyecto de Ley de Alienación Parental Regulación." Recuperado el 27 de julio de 2019 de https:// parlamento.gub.uy/documentosyleyes/ficha-asunto/125375.

Cámara de Representantes del Uruguay. 2015b, 5 de agosto. “Carpeta N 366 Proyecto de Ley División equitativa del tiempo de contacto de menores con sus padres. Modificación del artículo 34 del Código de la Niñez y Adolescencia." Recuperado el 27 de septiembre de 2019 de https://parlamento.gub.uy/documentosyleyes/ficha-asunto/125822/ficha_completa.

Cámara de Representantes del Uruguay. 2016, 13 de diciembre. “Sesión N²3 Diario N ${ }^{\circ}$ 4079." Recuperado el 30 de julio de 2019 de https: / parlamento.gub.uy.

Cámara de Representantes del Uruguay. 2018a, 3 de octubre. "Versión Taquigráfica № 1870 División Equitativa del tiempo de contacto de menores con sus padres." Recuperado el 28 de julio de 2019 de https: / / parlamento.gub.uy.

Cámara de Representantes del Uruguay. 2018b, 7 de noviembre. "Versión Taquigráfica Nº 1920 División Equitativa del tiempo de contacto de menores con sus padres." Recuperado el 30 de julio de 2019 de https: / / parlamento.gub.uy.

Cámara de Representantes del Uruguay. 2019, 7 de mayo. "Carpeta N 1275 Versión Taquigráfica $\mathrm{N}^{\circ}$ 2367." Recuperado el 28 de julio de 2019 de https:/ / parlamento.gub.uy.

Cámara de Senadores de Chile. 2013, 11 de abril. "Historia de la Ley N²0.680: Tercer Trámite Constitucional: Senado." Recuperado el 30 de julio de 2019 de https:/ / parlamento. gub.uy. 
Cámara de Senadores de Uruguay. 2016a, 29 de diciembre. “Diario de Sesión N 53 Tomo 5622". Recuperado de el 16 de agosto de 2019 de https:/ / parlamento.gub.uy.

Cámara de Senadores del Uruguay. 2013, 03 de febrero. "Carpeta 449 Proyecto de Ley Tenencia compartida Se modifican los artículos 34 y 37 de la Ley $\mathrm{N}^{\circ} 17.823$, de 7 de setiembre de 2004 (Código de la Niñez y la Adolescencia)." Recuperado el 30 de julio de 2019 de https://parlamento.gub.uy/documentosyleyes/ficha-asunto/128297/ ficha_completa.

Cámara de Senadores del Uruguay. 2016c, 22 de diciembre. "Versión Taquigráfica ํㅜ 752 Pensiones alimenticias decreta $\mathrm{u}$ homologadas judicialmente: Se crea un registro bajo la órbita del Banco de Previsión Social." Recuperado el 30 de julio de 2019 de https: / / parlamento.gub.uy.

Caminotti, Mariana. 2021, 6 de mayo. "La representación política de las mujeres en América Latina: dos décadas de avances y retos persistentes." Recuperado el 05 de julio de 2019 de https: / / reformaspoliticas.org/wp-content/uploads/2015/02/3-mcaminotti_genero.pdf.

Canal 4. 2018, 7 de septiembre. "Entrevista a Marcel Mantero "Somos muchos padres que estamos en esta situación". Recuperado el 24 de julio de 2019 de http:/ / www.canal4. com.uy/programas/vespertinas/videos/somos-muchos-padres-que-estamos-en-esta-situaci\%c3\%b3n.

Castiglioni, Rossana. 2019. “The Right and Gender Policies: The Expansion of Maternity Leave under the Piñera Administration in Chile." Paper prepared for delivery at the 2019 Congress of the Latin American Studies Association, May 24-27.

Chamberlain, Pam. 2011, 1 de marzo. "Father's rights groups threaten women's gains- and ther safety." Recuperado el 26 de febrero de 2020 de https:/ /www.politicalresearch. org/2011/03/01/fathers-rights-groups-threaten-womens-gains-and-their-safety.

Cheeseman, Nic., Juan Pablo Luna, Herbert Kitschelt, Dan Paget, Fernando Rosenblat, Kristen Sample, Sergio Toro, Jorge Valladares Molleda, Sam van der Staak y Yi- ting Wang. 2014. Politics Meets Policies: The Emergence of Programmatic Political Parties. Estocolmo: International IDEA.

Congreso Nacional de Chile. 2011, s.f. “Ley N²0.545 Modifica las normas sobre protección a la maternidad e incorpora el permiso postnatal parental." Recuperado el 15 de febrero de 2019 de https:/ / www.bcn.cl/leychile/navegar?idNorma=1030936.

Congreso Nacional de Chile. 2012, s.f. "Historia de la ley $N^{\circ}$ 20.680. Informe de Comisión de Constitución en sesión 140." Recuerado el 15 de febrero de 2019 de https:// www.bcn.cl/historiadelaley/fileadmin/file_ley/4280/HLD_4280_7f93c203e2386f972e54607e35a67e00.pdf.

Congreso Nacional de Chile. 2018, s.f. “Historia de la Ley No 20.680 Introduce modificaciones al código civil y a otros cuerpos legales, con el objeto de proteger la integridad del menor en caso de que sus padres vivan separados." Recuperado el 23 de Agosto de 2019 de https://www.bcn.cl/historiadelaley/fileadmin/file_ley/4280/HLD_4280_ 7f93c203e2386f972e54607e35a67e00.pdf.

Crhoy.com. 2017a, 21 de febrero. "Tablas para fijar pensiones alimentarias no discriminan, es lo más justo". Recuperado el 11 de enero de 2020 de https:/ /www.crhoy.com/nacionales/tablas-para-fijar-pensiones-alimentarias-no-discriminan-es-lo-mas-justo/.

Crhoy.com. 2017b, julio de 19. "Plan busca que menores vayan presos por no pagar pensión alimentaria." Recuperado el 11 de enero de 2020 de https://www.crhoy.com/nacionales/plan-busca-que-menores-vayan-presos-por-no-pagar-pension-alimentaria/.

Crhoy.com. 2018, 9 de septiembre. "Hombres mayores de 65 años no irán presos por pensión alimentaria." Recuperado el 11 de enero de 2020 de https://www.crhoy.com/nacionales/hombres-mayores-de-65-anos-no-irian-presos-por-pension-alimentaria/

Crowley, Jocelyn, E. 2008. Defiant Dads: Fathers' Rights Activists in America. Ithaca: Cornell University Press.

Cuesta, Laura y Daniel Meyer. 2014. "The Role of Child Support in the Economic Well-Being of Custodial-Mother Families in Less Developed Countries: The case of Colombia." International Journal of Law, Policy and the Family 28: 60-76. 
Cuesta, Laura., Merita Jokela, Mia Hakovirta y Holly Malerba. 2019. Who receives child support in Latin America? A comparative analyses of seven countries. Unpublished manuscript.

Diario Extra. 2015, 18 de marzo. "Morosos de pensión alimentaria sólo dormirían en la cárcel." Recuperado el 11 de enero de 2020 de http:/ /www.diarioextra.com/Noticia/detalle/255594/morosos-de-pension-alimentaria-solo-dormirian-en-la-carcel.

Diario Extra. 2016, 7 de marzo. "Policía detuvo 417 prófugos por pensión alimentaria en San José." Recuperado el 11 de enero de 2020 de https: / / www.diarioextra.com/Noticia / detalle/286220/policia-detuvo-417-profugos-por-pension-alimentaria-en-san-jose?fb_comment_id=1109499852443318_1109664142426889.

Diario Extra. 2018, 21 de junio. "Proponen seguro para quienes pagan pensión alimentaria." Recuperado el 11 de enero de 2020 de https:/ /www.diarioextra.com/Noticia/detalle/362299/proponen-seguro-para-quienes-pagan-pension-alimentaria.

El Mostrador. 2017, 10 de setiembre. "Un aumento de alrededor del 6\% del PIB pér cápita tendría Chile si los hombres participaran mpas en las labores del hogar." Recuperado el 30 de julio de 2019 de https://m.elmostrador.cl/braga/2017/09/10/un-aumento-de-alrededor-del-6-del-pib-per-capita-tendria-chile-si-los-hombres-participaranmas-en-las-labores-del-hogar/.

El Observador. 2019, 28 de marzo. “¿Cómo funciona el nuevo registro de pensiones alimenticias?" Recuperado el 20 de setiembre de 2019 de https:/ / www.elobservador.com.uy / nota/-como-funciona-el-nuevo-registro-de-pensiones-alimenticias--201932716957.

El País. 2016, 23 de octubre. “Un país en "guerra conyugal”. Recuperado el 30 de julio de 2019 de https:/ / www.elpais.com.uy/informacion/pais-guerra-conyugal.html.

El País. 2018, 29 de setiembre. "La guerra que nadie gana." Recuperado el 11 de enero de 2019 de https:/ / www.elpais.com.uy/que-pasa/guerra-nadie-gana.html.

El País.cr. 2019, 1 de mayo. “Diputados del PLN y del PAC fijan agenda para nuevo año legislativo." Recuperado el 11 de enero de 2020 de https:/ /www.elpais.cr/2019/05/01/ diputados-del-pln-y-del-pac-fijan-agenda-para-nuevo-ano-legislativo/.

Filus Pater. 2019. "Información sobre Filus Pater." Recuperado el 12 de setiembre de 2019 de https://www.facebook.com/pg/Fundaci\%C3\%B3n-Filius-Pater-129258827121144/ posts/.

Fleckenstein, Timo., y Soohyun Lee. 2014. "The Politics of Postindustrial Social Policy." Comparative Political Studies, 47(4): 601-630.

Flood, Michael. (2012). "Separated fathers and the 'Fathers' Rights' Movement. "Journal of Family Studies 18(3): 231-241.

Folbre, Nancy. 2012. "Who Pays for the Kids? Gender and the Structure of Constraints." En For Love and Money: Care Provision in the United States, editado por Nancy Folbre. Nueva York: Russell Sage Foundation.

Friðriksdóttir, Hrefna. 2014. "Nordic family law: new framework - new fatherhoods" En $\mathrm{Fa}$ therhood in the Nordic Welfare states: Comparing care policies and practice, editado por Tine Rostgaard. Oxford: Policy Press Scholarship Online. 28-75.

Gustá, Ana Laura., Nancy Madera y Mariana Caminotti. 2017. “Governance Models of Gender Policy Machineries under Left and Right Governments in Latin America." Social Politics 24(4): 452-480.

Hobson, Barbara y David Morgan. 2002. "Introduction: Making Men into Fathers." Making Men into Fathers: Men, Masculinities and the Social Politics of Fatherhood, editado por Barbara Hobson y David Morgan. Cambridge: Cambridge University Press. 101-124.

Htun, Mala., y Laureal Weldon. 2010. "When Do Governments Promote Women's Rights? A Framework for the Comparative Analysis of Sex Equality Policy." Perspectives on Politics, 8(1): 207-216.

INAMU. 2019, 29 de julio. “Criterio N 19.455 Código Procesal de Familia." Recuperado el 11 de enero de 2020 de Departamento de Servicios Técnicos.

INAMU. 2019, 30 de setiembre. "INAMU cuestiona portillos legales para incumplimiento del pago de pensiones alimentarias." Recuperado el 16 de enero de 2020 de https:/ / 
www.inamu.go.cr/web/inamu/inamu-cuestiona-portillos-legales-para-incumplimiento-del-pago-de-pensiones-alimentarias.

Informa-tico. 2018, 13 de abril. "Defensoría plantea consulta ante Sala IV sobre Código Procesal de Familia." Recuperado el 11 de enero de 2020 de https:/ /www.informa-tico. com/13-04-2018/defensoria-plantea-consulta-sala-iv-codigo-procesal-familia.

Kaye, Miranda., y Julia Tolmie. 1998. "Discoursing dads: the rethorical devices of fathers' rights groups." Melbourne University Law Review, 162-194.

Kramerman, Sheila., y Peter Moss. 2009. The Politics of Parental Leave Policy. Bristol: The Policy Press.

La Nación. 2016, 9 de enero. "Padres por pensión claman por eliminar salario escolar." Recuperado el 10 de enero de 2020 de https://www.nacion.com/sucesos/judiciales/ padres-con-pension-claman-por-eliminar-salario-escolar/E7WTMQU7SVGVPJBL5OU56CNFDQ/story/.

La Nación. 2017a, 9 de febrero. "Proponen que las pensiones alimentarias oscilen entre $\$ 38.000$ y $\Varangle 720.000$ por niño." Recuperado el 11 de enero de 2020 de https:/ /www. nacion.com/el-pais/politica/proponen-que-las-pensiones-alimentarias-oscilen-entre-c-38-000-y-c-720-000-por-nino/IJLS3FEHUJGITK7EWS7BK4TNCE/story/.

La Nación. 2017b, 11 de febrero. "Jueza expone 17 argumentos para sepultar idea de una tabla de pensiones alimentarias." Recuperado el 11 de enero de 2020 de https:// www.nacion.com/el-pais/politica/jueza-expone-17-argumentos-para-sepultar-idea-de-una-tabla-de-pensiones-alimentarias/BBQ27SLO25AF3HHYZD2D$5 \mathrm{JPMRY} /$ story/.

La Prensa Libre. 2016a, 25 de febrero. "Importante fallo Sala IV sobre pensión alimentaria." Recuperado el 11 de enero de 2020 de http:/ / www.laprensalibre.cr/Noticias/detalle/59468/importante-fallo-de-sala-iv-sobre-pension-alimentaria.

La Prensa Libre. 2016b, 11 de mayo. "Proyecto que evita cárcel por pensión alimentaria está estancado." Recuperado el 11 de enero de 2020 de https://www.laprensalibre.cr/ Noticias/detalle/68671/proyecto-que-evita-carcel-por-pension-alimentaria-esta-estancado.

La Tercera. 2013b, 12 de mayo. "El 60\% de los demandados por pensiones de alimentos no paga, según Poder Judicial." Recuperado el 30 de julio de 2019 de: https://www. latercera.com/noticia/el-60-de-los-demandados-por-pensiones-de-alimentos-no-paga-segun-poder-judicial/.

La Tercera. 2013a, 21 de octubre. "Organización de padres acusa que Ley de Igualdad Parental no se está cumpliendo y Sernam apela a "período de adaptación"." Recuperado el 30 de julio de 2019 de: https:/ / www.latercera.com/noticia/organizacion-de-padresacusa-que-ley-de-igualdad-parental-no-se-esta-cumpliendo-y-sernam-apela-a-periodo-de-adaptacion/.

Lagos, Pilar. 2011, 09 de marzo. "El síndrome de alienación parental: una realidad latente." Recuperado el 11 de junio de https://www.emol.com/noticias/Tendencias/2011/03/11/734921/El-sindrome-de-alienacion-parental-una-realidad-latente. html

León, Wendy. 2020. "Las demandas de organizaciones de padres separados al Estado: Inventario e interpretación a partir de organizaciones de Costa Rica y Uruguay, 2016-2017". Tesis para optar por el grado de Licenciada en Ciecias Políticas. San José: UCR.

Lippman, Laura., y Braford Wilcox. 2014. "Family Instability and Early Child Childhood Health in the Developing World." An International Report from Child Trends. Recuperado el 13 de junio de 2019 de https: / / www.researchgate.net/publication/281550939_Family_instability_and_early_childhood_health_in_the_developing_world_en_World_ Family_Map_2014_Mapping_Family_Change_and_Child_Well-being_Outcomes_ New_York-Barcelona_2014_pp_49-64.

Madera, Nancy., Mariana Caminotti y Ana Laura Gustá. 2017. "Governance Models of Gender Policy Machineries under Left and Right Governments in Latin America." Social Politics 24(4): 452-80. 
Mareco, María. 2018, 23 de marzo. “Ley 19.480: Se crea el registro de personas obligadas al pago de pensiones alimenticias a cargo del BPS." Recuperado el 18 de julio de 2019 de http:/ / www.cronicas.com.uy/columnas/ley-19-480-se-crea-registro-personas-obligadas-al-pago-pensiones-alimenticias-cargo-del-bps/.

Martínez Franzoni, Juliana. 2021. "Understanding the State Regulation of Fatherhood in Latin America: Complementary versus Co-responsible." Journal of Latin American Studies 53(3): 521-545.

Martínez Franzoni, Juliana y Wendy Arias. 2021. "Trayectorias de la regulación estatal de la paternidad en América Latina, 2000-2019." Manuscrito en proceso de evaluación de pares.

Marzonetto, Gabriela. 2019. "La política de los programas de cuidado infantil en América Latina: Un análisis comparado de Argentina, Chile y Uruguay (2005-2015)." Tesis doctoral. Buenos Aires: UNSAM.

McBride Stetson, Dorothy y Amy Mazur. 1995. Comparative state feminism. London: Sage.

McBride, Dorothy y Amy Mazur. 2010. The politics of state feminism: Innovation in comparative research. Philadelphia, PA: Temple University Press.

Michell, Sonya y Rianne Mahon. 2002. Chile Care Policy at a Crossroads: Gender and Welfare State Restructuring. London: Routledge.

Milanich, Nara. 2015. "Is a Change in the Power Structures of Society: The Politics of Family Law in Twentieth Century Chile and Latin America." Law and History Review 33(4): 767-802.

Morgan, Kimberly. 2006. Working Mothers and the Welfare State. Stanford, California: Stanford University Press.

Noticia Monumental. 2017, 13 de mayo. "Sitio web permitirá calcular pago de pensiones alimentarias." Recuperado el 11 de enero de 2020 de http://www.monumental.co. cr/2017/05/13/sitio-web-permitira-calcular-pago-de-pensiones-alimentarias/.

Pandiani, Y. (10 de Octubre de 2019). (J. Martinez Franzoni, Entrevistador) Montevideo , Uruguay.

Papá Presente. 2019, s.f. "Qué es el SAP." Recuperado el 12 de setiembre de 2019 de http:/ / www.papapresente.org/contenido.asp?Id=1\&Titulo=Qu\%E9\%20es\%20el\%20SAP.

Papás Por Siempre. 2019, s.f. "El problema social y jurídico." Recuperado el 12 de setiembre de 2019 de https:/ / www.papasporsiempre.cl/el-problema.html.

Parlamento del Uruguay. 1994, 21 de noviembre. "Ley N 16.603 Código Civil." Recuperado el 30 de julio de 2019 de https:/ / parlamento.gub.uy.

Parlamento del Uruguay. 2004, 14 de septiembre. "Ley $\mathrm{N}^{\circ} 17.823$ Código de la Niñez y Adolescencia." Recuperado el 17 de Julio de 2019 de https:/ / parlamento.gub.uy.

Parlamento del Uruguay. 2005, 10 de noviembre. "Ley No 17.957 Registro de Deudores Alimentarios." Recuperado el 30 de julio de 2019 de https:/ / parlamento.gub.uy.

Parlamento del Uruguay. 2017, 17 de enero. "Ley No 19.480 Registro de Personas Obligadas Alimenticias con Retención de Haberes." Montevideo, Uruguay. Recuperado el 30 de julio de 2019 de https: / / parlamento.gub.uy.

Parlamento del Uruguay. 2019, 19 de enero. “Ley N 19.727 Pensión Alimenticia se establece la imposición de efectuar declaración jurada de bienes e ingresos de los deudores alimentarios." Recuperado el 30 de julio de 2019 de https: / parlamento.gub.uy.

Pateman, Carol. 1988. El Contrato Sexual. Stanford: Stanford University Press.

Pribble, Jennifer. 2013. Welfare and Party Politics in Latin America. Cambridge University Press.

Primera Hora. 2019, 30 de marzo. "Todo por nuestros hijos" quiere marcar presencia en San José." Recuperado el 11 de enero de 2020 de http://www.primerahora.com.uy/hijos-quiere-marcar-presencia-san-jose /.

Reyes, Catherine. 2018. Presidentas, poder y cambios pro mujer. En La política siempre ha sido cosa de mujeres: Elecciones y Protagonistas en Chile y la Región, editado por Lucía Miranda y Julieta Suárez-Cao. Santiago, Chile: FLACSO Chile. 25-40.

Sala Constitucional. 2013, 16 de diciembre de 2013. “Res. N 16821 - 2013 Procesos de aumento, rebajo y exoneración de pensiones alimentarias. Artículo 58 de la Ley Número 
7654 denominada Ley de Pensiones Alimentarias." Recuperado el 7 de noviembre de 2019 de https:/ / nexuspj.poder-judicial.go.cr.

Sala Constitucional. 2014, 27 de junio. "Acción de inconstitucionalidad contra el artículo 14 de la ley de Pensiones Alimentarias 15-001234-007-CO-UNED." Recuperado el 9 de noviembre de 2019 https:/ / nexuspj.poder-judicial.go.cr.

Sala Constitucional. 2015b, 30 de junio. "Res. N²324-2015 Acción de Inconstitucionalidad Ley de Pensiones Alimentarias N7654." Recuperado el 9 de noviembre de 2019 de https://nexuspj.poder-judicial.go.cr.

Sala Constitucional. 2015a, 13 de mayo. "Res. Nº6791 - 2015 Apremio por falta de pago del salario escolar a los obligados alimentarios." Recuperado el 11 de noviembre de 2019 de https://nexuspj.poder-judicial.go.cr.

Sala Constitucional. 2016, 20 de enero. “Res. N 00802- 2016 Acción de Inconstitucionalidad Práctica de los Juzgados de Pensiones Alimentarias del país, de fijar el monto de los gastos de entrada a clases." Recuperado el 31 de octubre de 2019 de https: / / nexuspj. poder-judicial.go.cr.

Sala Constitucional. 2018, 18 de mayo. "Res. N 2018007979 Consulta facultativa de constitucionalidad interpuesta por la Defensoría de los Habitantes." Recuperado el 17 de enero de 2020 de https: / /nexuspj.poder-judicial.go.cr.

Scott, Elizabeth. 1992. "Pluralism, Parental Preference, and Child Custody." California Law Review, 80(3): 615-72.

The Clinic. 2015, 31 de agosto. "El vacío legal que no resuelve el AUC: madres lesbianas no pueden reconcer a sus hijos." Recuperado el 30 de julio de 2019 de https://www. theclinic.cl/2015/08/31/el-vacio-legal-que-no-resuelve-el-auc-madres-lesbianas-nopueden-reconocer-a-sus-hijos/.

Tobar Ríos, Marcela. 2008. Mujeres y Política. Santiago, Chile: FLACSO Chile.

Tsebelis, George. 2002. Veto Players: How Political Institutions Work. Princeton: Princeton University Press.

Recibido: 4 de mayo de 2020

Aceptado: 18 de junio de 2021

Juliana Martínez Franzoni es Catedrática Humboldt 2021 en la Universidad de Costa Rica y acaba de recibir el premio George Foster otorgado por la Fundación Humboldt a trayectorias sobresalientes de investigación. Se enfoca en el análisis comparado de la política social en América Latina, incluyendo las de cuidados, con particular énfasis en arquitecturas y procesos de cambio. Su último libro, escrito con Diego Sánchez-Ancochea, investigador de la Universidad de Oxford, se titula La búsqueda de la política social en el Sur global: actores, ideas y arquitecturas. Es co-editora de la revista Social Politics. Email: martinezfranzoni@gmail.com

Adriana Fernández es profesora en la Universidad de Costa Rica e investigadora en el Instituto de Investigaciones Sociales. Tiene una licenciatura en Ciencias Políticas por la Universidad de Costa Rica y su trabajo se enfoca en migraciones, políticas públicas y género. Email: adrianafdezcalderon@gmail.com 